\title{
LOS EMPRESARIOS ANTE LOS REGÍMENES DEMOCRÁTICOS EN ESPAÑA: LA II REPÚBLICA Y LA TRANSICIÓN*
}

\author{
Ángeles González Fernández
}

El análisis comparativo de momentos históricos diferentes resulta sumamente sugestivo, pero deviene un ejercicio no exento de riesgos porque no todo es susceptible de comparación. El tiempo no pasa en vano y el presente siempre está condicionado por la experiencia del pasado. Esto es especialmente cierto en el caso de la transición de la dictadura franquista a la democracia. Todo su desarrollo se realizó bajo la sombra omnipresente de un pasado trágico que nadie deseaba volviera a ocurrir. El recuerdo de la Guerra Civil y de la dictadura franquista impulsó actitudes de prudencia y moderación que facilitaron el acuerdo entre actores políticos y agentes sociales sobre el procedimiento a seguir y el objetivo final, el éxito del cambio a la democracia. Acuerdo imposible en los años treinta, en los que la República -en palabras de S. Juliá- fue vivida como negación de todo lo anterior y no como culminación de un proceso de democratización basado en un consenso generalizado. Es cierto que existió acuerdo, pero como subraya G. Sánchez Recio, limitado a los grupos firmantes del Pacto de San Sebastián. El incumplimiento de las condiciones fijadas por los grupos parlamentarios de derecha $-y$, en otro orden de cosas, también por las organizaciones patronales-impidió su ampliación. Un consenso, pues, a todas luces insuficiente que, a la postre, se convirtió en el mayor obstáculo para la consolidación de la República ${ }^{1}$.

\footnotetext{
* Este trabajo se inserta dentro del Proyecto de Investigación HUM2005-03816 de la DGICYT, «Del consenso constitucional al enfrentamiento partidista en España, 1977-2004».

1. Cfr. Agullar, Paloma, Memoria y olvido de la guerra civil española, Madrid, 1996, p. 56. Sobre el consenso LEMUS LÓPEZ, Encarnación, En Hamelin... La Transición española más allá de la frontera. Oviedo, Septem Ed., 2001; Juliá, Santos, "Orígenes sociales de la democracia en España", en REDERO SAN ROMÁn, Manuel (ed.), "La Transición a la democracia en España», Ayer, n. 15 (1994), p. 177; SÁNCHEZ RECIO, Glicerio, "El reformismo republicano y la modernización democrática», Pasado y Memoria. Revista de Historia Contemporánea, n. ${ }^{\circ} 2$ (2003), pp. 18-19; CABRERA, Mercedes,
} 
Éste es uno de los elementos que plantea serias dificultades para abordar un análisis comparativo de ambos períodos, pero no el único. El proceso de modernización económica que había conocido la sociedad española a lo largo de los años sesenta del siglo XX posibilitó el desarrollo de una sociedad de clases medias en posesión de un sistema de valores y comportamientos muy alejados de los existentes cuarenta años atrás, caracterizados por una aguda polarización social e ideológica. Del mismo modo, el contexto internacional era claramente diferente. La crisis de las democracias y el auge de los fascismos no guardan relación alguna con el escenario europeo de mediados de los setenta, en los que tan sólo Portugal, Grecia y España mantenían regímenes autoritarios; tampoco con el escenario internacional, marcado por la distensión de la Guerra Fría. De otra parte, la pertenencia de España al bloque occidental y su dependencia económica respecto de Estados Unidos y de la Comunidad Económica Europea, especialmente tras la firma del Tratado Preferencial de 1970, favoreció el desarrollo de tendencias aperturistas, el crecimiento de la oposición y, desde luego, el propio proceso de transición democrática. Éste era, precisamente, el requisito sine qua non para su plena integración y así fue considerado por los protagonistas del cambio en los años setenta.

Pese a que se trata de dos modelos claramente distintos y así lo han subrayado aquellos historiadores y politólogos que han planteado la cuestión, el paralelismo entre ambos -cuestión que, por otro lado, se está replanteando en el debate político actual- fue abordado con relativa frecuencia en los medios de comunicación a lo largo de la segunda mitad de los setenta y primeros ochenta. En unos casos para recalcar los peligros que era preciso evitar; en otros, para destacar la presencia de una coyuntura económica similar, marcada por la crisis, el paro y una intensa conflictividad social. Así lo expuso -entre otros- Ferrer Salat, presidente de la CEOE, "Como en 1931, por segunda vez en 1975, tenemos que enfrentarnos a una doble crisis: la económica y la política»².

Así pues, abordar un análisis comparativo de los empresarios, de su discurso, actitudes y estrategias ante procesos poco susceptibles de un correlato ajustado, supone un reto cuando menos complejo ${ }^{3}$. No obstante, la dificultad en este caso concreto se ve un tanto aminorada por el hecho de que, en líneas

La patronal ante la II República. Organizaciones y estrategias (1931-1936), Madrid, Siglo XXI, 1983, p. 6; BENGOECHEA, Soledad, Reacció en temps de canvis. La patronal catalana davant la República (19311936), Barcelona, Societat Catalana d'Estudis Històrics, 2005, p. 26.

2. JUliÁ, Santos, "Orígenes sociales de la democracia en España», pp. 165-188. CruZ ARTACHO, Salvador, "Oligarquía y caciquismo. ¿Una constante y un problema en la política española del siglo XX?», en MORALES MOYA, Antonio (coord.), El difícil camino a la democracia, Madrid, Sociedad Estatal Nuevo Milenio, 2001, especialmente pp. 75-83. ÁlVArEZ TARDío, Manuel, El camino a la democracia en España, 1931-1978, Madrid, Gota a Gota Ediciones, 2005. A modo de ejemplo, CONDE DE MONTARLo, "Ante la meta, los últimos metros son más difíciles»; PAlafoX, J., "En los años treinta, España también fue diferente»; LAín ENTRALGO, P., "Cincuenta años después», El País, 29- 4-1977, 28-10-1979 y 25-3-1980. La cita de Ferrer en MARTínez Soler, José A., Los empresarios ante la crisis económica, Barcelona, Grijalbo, 1982, p. 153.

3. Véase CABRERA, Mercedes, «Empresarios y políticos en la democracia. De la crisis económica a las incertidumbres», Economía industrial, 349-350 (2003), I y II, pp. 51-62. 
generales, el discurso y las prácticas de los empresarios giraron en torno a la defensa de los mismos principios: la economía de mercado (siempre condicionada por la demanda de protección al Estado de los intereses superiores de la Nación), la propiedad privada y la libertad de iniciativa empresarial. Del mismo modo, sus estrategias pretendían lograr un mismo objetivo, la preservación de su proximidad a los ámbitos de decisión política para influir sobre ellos y asegurar la defensa de sus intereses.

Esto es así porque los empresarios poseen una misma cultura definida, entre otros valores, por el principio de autoridad, la afirmación de la existencia de una comunidad natural entre el patrono y sus obreros y el temor a cualquier tipo de innovación que pueda poner en peligro la posición adquirida y el orden existente, que se ha mantenido en gran medida inalterada. Con todo, siempre se ha de tener presente tres cuestiones: primero, que no puede establecerse una caracterización única al mundo empresarial porque sus posiciones ideológicas y políticas pueden ser tan distintas como, de hecho, lo son sus intereses económicos; segundo, la naturaleza de los negocios está sometida a variaciones en función del propio desarrollo de la economía, nacional e internacional, tanto como de la política económica del Estado; tercero, y consecuencia de lo anterior, los negocios no siempre solicitan lo mismo de los poderes públicos ni en los mismos términos ${ }^{4}$. En suma, la experiencia del régimen dictatorial -en términos económicos y políticos- así como el bagaje adquirido por los empresarios a lo largo del franquismo tuvo un impacto determinante en sus actitudes durante la transición a la democracia. Así pues, su actuación y estrategias -pese a las evidentes semejanzas- responden a contextos diferentes y sólo alcanzan su pleno sentido si se inscriben en el proceso en que tuvieron lugar.

Resulta meridianamente claro que la naturaleza de los negocios de los empresarios españoles en el último cuarto de siglo era sustancialmente distinta a la existente en los años treinta como resultado de la interacción de factores diversos. La transformación de las relaciones laborales en el campo y la reforma de la propiedad de la tierra -uno de los objetivos básicos del régimen republicano y que mayor oposición suscitó entre el empresariado al considerar que estaba en juego el concepto de propiedad privada-ya no constituía una cuestión prioritaria. La modernización y ajuste estructural que la agricultura española había experimentado en los años sesenta la hacía innecesaria, aunque la reforma de la propiedad figurara en el programa de algunos partidos políticos ${ }^{5}$. Por otra parte, la reducción de la aportación de la agricultura a la economía como resultado de la industrialización acelerada se tradujo en una sensible contracción de la capacidad de influencia política de los propietarios de tierra frente a industriales y financieros por primera vez en la Historia de España. Los intereses agrarios

4. Piqueras Arenas, José A., "Negocios y política en el siglo XIX español», en Paniagua, Javier y Piqueras, José A. (eds.), Poder económico y poder político, Valencia, Centro Francisco Tomás y Valiente UNED Alzira-Valencia/Fundación Instituto Historia Social, 1998, p. 20.

5. Sobre la transformación de la agricultura en los sesenta, véase NAREDO, José Manuel, La evolución de la agricultura en España (1940-1990), Granada, Universidad de Granada, 1996. 
quedaron, pues, relegados a un segundo plano y, en consecuencia, el conflicto que enfrentó a ambos durante la II República, especialmente durante el segundo bienio, no alcanzó niveles similares ${ }^{6}$.

De otro lado, la aprobación de la ley de convenios colectivos de 1958 introdujo una cultura de negociación en las relaciones laborales, escasamente presente en los años treinta, momento en que la actuación de los comités paritarios provocó notorias resistencias en el mundo empresarial y el rechazo de los sindicatos adscritos a la CNT. Pese a las competencias que todavía se reservaba el Estado en este campo, a lo largo de los últimos años del franquismo se difundieron y consolidaron nuevas prácticas negociadoras. Los contactos informales y directos entre los empresarios y los auténticos representantes de los trabajadores, básicamente militantes de Comisiones Obreras, tendieron a convertirse en el cauce por excelencia para la solución de los conflictos, al margen del sindicato vertical. Esa cultura de negociación, en fin, preparó el camino para que los empresarios postularan la necesidad de un gran pacto social con las organizaciones sindicales como requisito previo para abordar la reactivación económica.

Al mismo tiempo, el panorama sindical había conocido transformaciones significativas, sustentadas en gran medida en la experiencia dictatorial, que se tradujeron en lo que podría calificarse como una actuación más responsable, tanto en términos políticos como estrictamente sindicales. $\mathrm{Y}$ a ese rasgo no fue ajena la desaparición de la CNT como organización de masas. Su estrategia insurreccional contra la República casi desde el mismo momento de su proclamación, fue acompañada por una extraordinaria escalada de huelgas en demanda de peticiones maximalistas que colocaron a los empresarios, especialmente a los pequeños y medianos, en situaciones límite en muchas ocasiones. Un radicalismo al que, además, se sumó UGT que acabó asumiendo estrategias de oposición al sistema ${ }^{7}$.

A mediados de los años setenta tanto CC.OO. como UGT llevaron a cabo intensas movilizaciones y encabezaron un extraordinario movimiento huelguístico, con objetivos económicos pero con un claro componente político, en

\footnotetext{
6. La oposición de los propietarios agrarios a la política económica republicana se basaba -a su juicio- en la primacía dada a los intereses de los industriales en claro perjuicio de los intereses nacionales al ser España un país fundamentalmente agrario. HeRMIDA REVILLAS, Carlos, «La política triguera en España y sus repercusiones en el bloque de poder: 1890-1936", Historia y Comunicación Social, n. 1 (1996), pp. 59-60; CABRERA, Mercedes, "Historia de un desencuentro: la patronal ante la política económica de la Segunda República (1931-1933)", Pasado y Memoria. Revista de Historia Contemporánea, n..$^{\circ}$ (2003), pp. 33-52.

7. «Los patronos tienen cada día la sensación de que al día siguiente no sabrán cuál será el precio de coste, ni cuáles las reivindicaciones obreras, puesto que piden locuras». M. Maura en estas declaraciones se refería a los empresarios catalanes, aunque pueden hacerse extensiva a todo el país. VIDARTE, Juan Simeón, Las Cortes Constituyentes de 1931-1933. Testimonio del primer secretario del Congreso de Diputados, Barcelona, Grijalbo, 1976 p. 107. Cfr. REDERO SAN ROMÁN, Manuel, «El sindicalismo mayoritario en la experiencia democrática de la Segunda República", en ARÓSTEGUI, Julio, La República de los trabajadores. La Segunda República y el mundo del trabajo, Madrid, Fundación Largo Caballero, 2006, pp. 110-130.
} 
apoyo a una salida rupturista de la dictadura. Sin embargo, la firma de los Pactos de la Moncloa y la consiguiente subordinación a los partidos políticos supuso la adopción de estrategias desmovilizadoras con la finalidad de consolidar la democracia y evitar el peligro de una involución. Cierto es que la conflictividad siguió siendo elevada hasta 1982, pero la negociación colectiva se atuvo a los objetivos estipulados en la política macroeconómica y en ningún caso alcanzó niveles de violencia similares a los registrados durante la República. Y en ello tuvo una influencia determinante el desarrollo de una política de pactos sociales que operó como factor de contención del conflicto social y tranquilizó a los empresarios al proporcionar un marco de referencia estable en sus negociaciones con políticos y sindicatos ${ }^{8}$.

Sin duda se trata de cambios trascendentes. No obstante, en estas páginas sostendremos, entre otros argumentos fuertes que facilitan la comparación, que más determinante e innovador resultó ser la eclosión de un modelo asociativo empresarial de nuevo tipo. Como es sabido, el individualismo es uno de los rasgos definitorios de la cultura empresarial. Sin embargo, la acción individual resulta ineficaz en determinadas coyunturas, aquéllas en las que perciben un riesgo para sus negocios e incluso para su propia supervivencia como empresarios. Más aún si esa percepción de riesgo procede de la inoperancia o debilidad de los poderes públicos, especialmente en contextos de crisis o cambio político. Ante esas circunstancias, que suelen ser vividas con notoria alarma y no poco dramatismo, los empresarios renunciarán a su tradicional individualismo y recurrirán abiertamente a la acción colectiva, bien a través de nuevos vínculos asociativos o, si se da el caso, a la refundación y/o reforzamiento de los existentes. Por otro lado, la organización de los intereses es la pieza clave para articular las relaciones de los empresarios con los poderes públicos y con los sindicatos, no sólo por su condición de cauce por excelencia para la acción colectiva, también por el hecho de que la dinámica organizativa tiene un papel fundamental en el proceso de identificación y definición de intereses?.

En los años treinta, los intentos realizados para construir un sistema organizativo unitario naufragaron y no puede aducirse que la heterogeneidad de sus intereses fuera la causa única y principal, puesto que es un rasgo inherente al mundo empresarial, competitivo e individualista por definición. Resulta obvio que en ese fracaso influyeron sobremanera la desigual repercusión de la crisis económica a nivel sectorial, el acusado localismo y los notorios desequilibrios regionales tanto como el mismo proceso de modernización del sistema produc-

8. Redero SAn RomÁn, Manuel y Pérez Delgado, Tomás, «Sindicalismo y transición política en España», en REDERO SAN ROMÁN, Manuel, La Transición a la democracia en España, Ayer, n. ${ }^{\circ} 15$ (1994), pp. 189-222. Cabe señalar que las ocupaciones de fincas llevadas a cabo por el SOC en Andalucía tuvieron carácter simbólico y en raras ocasiones dieron lugar a incidentes violentos. PÉReZ DíAZ, Víctor, "Los empresarios y la clase política», Papeles de Economía Española, n. ${ }^{\circ} 22$ (1985), p. 70.

9. LANZALACO, Luca, D'all impresa all'associazione. Le organizzacione degli imprenditore: la Confindustria in prospectiva comparata, Milano, Franco Angeli, 1990, pp. 17-18. JULIÁ, Santos, "Orígenes sociales de la democracia», pp. 170-171. 
tivo en curso ${ }^{10}$. No obstante, las modalidades de agregación de los grupos y de objetivación de sus intereses en una organización dependen en gran medida del Estado, de la manera en que las reconoce o las descalifica, y de la competencia que caracteriza las relaciones entre los distintos grupos de interés. Y la II República no pretendió una representación equilibrada entre empresarios y trabajadores precisamente porque entre sus objetivos se hallaba dar satisfacción a los preteridos intereses de éstos últimos. La actuación de Largo Caballero como ministro de Trabajo estuvo orientada a conseguir una posición hegemónica de los "trabajadores organizados sindicalmente», lo que en su caso quería decir de la UGT, no sólo en el sistema de relaciones laborales sino también en los ámbitos de decisión política, aquellos que hasta 1931 habían monopolizado los empresarios ${ }^{11}$.

El panorama fue radicalmente distinto durante la transición a la democracia, en buena medida gracias al legado franquista. La creación forzada de un sistema representativo obligatorio y único, aunque subordinado a la línea política de la Organización Sindical, proporcionó a los empresarios unos recursos y una experiencia organizativa de los que nunca habían dispuesto con anterioridad. Sobre ellos se sustentó en buena medida la gestación de un modelo nuevo, basado en la libertad, voluntariedad y en un «equilibrio consistente» entre los diversos intereses del mundo empresarial. Desde luego su gestación no estuvo exenta de serias dificultades pero la necesidad de una organización única y representativa tanto ante los poderes públicos como ante los sindicatos, diluyó las rivalidades y las competencias internas. Al mismo tiempo, el gobierno de Suárez alentó el acuerdo entre las asociaciones existentes precisamente porque precisaba de un interlocutor único para contrapesar el poder de los sindicatos, alineado con las tesis rupturistas, y asegurar su colaboración en la ejecución de la política económica ${ }^{12}$.

10. Cfr. STREECK, Wolfgang, Interest heterogenity and organizing capacity: two class logics of collective action, Madrid, Instituto Juan March, 1990. Las peculiaridades organizativas de industriales vascos y catalanes motivadas por razones históricas, políticas y socioeconómicas, en CABRERA, Mercedes, La patronal ante la II República, pp. 57-59. Las reticencias de FTN a una organización patronal unitaria, en CALVO, Ángel, "El Foment del Treball Nacional davant d'un nou horitzó», L'Avenç, revista d'història, n. ${ }^{\circ} 138$ (1990), pp. 56-56.

11. AZAGRA Ros, Joaquín, "Entre dos 98»: crecimiento económico y régimen político», en PANIAGUA, Javier y PIQUERAS, José A. (eds.), Poder económico y poder político, pp. 131-159. ARÓsTEGUI, Julio, "Largo Caballero, ministro de Trabajo», en VV. AA., La II República española. El primer bienio, Madrid, Siglo XXI, 1987, p. 61. JuLIÁ, Santos, "Objetivos políticos de la legislación laboral», en Ibidem, pp. 30-32.

12. SCHMitTER, Philippe C., y LANZALACO, Luca, «Las regiones y la organización de los intereses comerciales», en SOLÉ, Carlota (comp.), Corporatismo y diferenciación regional, Madrid, MTSS, 1987, p. 279. GONZÁLEZ FERNÁNDEZ, Ángeles, "La representación de los intereses empresariales en el franquismo: los Consejos Provinciales de Empresarios, 1965-1975», Pasado y Memoria. Revista de Historia Contemporánea, n. ${ }^{\circ} 3$ (2004), pp.73-92; «El mundo no empieza hoy ni partimos de la nada. El Consejo Nacional de Empresarios ante la reforma sindical», en MATEOS, Abdón y Herrerín, Ángel (eds.), La España del Presente: de la dictadura a la democracia. Historia del Presente, n. ${ }^{\circ} 3$ (2006), pp. 271-288. 


\section{EMPRESARIOS Y DEMOCRACIA}

Una de las paradojas más conmovedoras que se registra en lo que podríamos convenir en denominar cultura empresarial es aquella que tiene que ver con su percepción del cambio y la innovación. Si bien es cierto que, por definición, el empresariado está abierto al riesgo, sólo está dispuesto a asumirlo en la medida que controla los factores que lo enmarcan. Los avatares de la política española constituyeron, de manera recurrente, una fuente de incertidumbres añadidas que impactaban sobre sus expectativas de negocios. Y, sin embargo, los empresarios precisan de un horizonte seguro para sus inversiones que -en una economía no integrada en los flujos internacionales- sólo puede provenir del marco político, sea éste democrático o no. Incluso puede ser irrelevante la antinomia entre economía de mercado y economía intervenida; naturalmente, sólo hasta cierto punto, puesto que su total ausencia implicaría directamente su desaparición.

«Hay que tener en cuenta, además, que a un empresario, en cuanto tal, lo que de verdad le importa, para proyectar su acción en el futuro, no es tanto que el sistema sea más o menos de mercado, como que sea un sistema de referencias claras (...) A un empresario lo que le interesa del marco institucional es su precisión aún más que su bondad general. Lo peor es el vacío» ${ }^{13}$.

Podría argumentarse, entonces, que los empresarios son neutros respecto al régimen político. Nada más lejos de la realidad. Existe un vínculo inextricable entre política y negocios de forma que su actitud hacia un sistema político dado estará en función del establecimiento de las condiciones adecuadas para su desenvolvimiento como empresarios y mantenga cauces -formales o informalesque les permitan una relación de proximidad a los ámbitos de decisión política e influir sobre ellos ${ }^{14}$. En otras palabras, siempre intentarán mantenerse al lado de los poderes públicos puesto que son los que definen las reglas del marco económico y de relaciones laborales a las que deben atenerse en su actividad como empresarios. Esa relación de dependencia, sin embargo, no es unilateral. Los gobiernos precisan de la colaboración de los hombres de negocios para ejecutar su política económica. Más aún, deben asegurar unos niveles de crecimiento

13. PASCUAL, Julio, "El empresario español de la transición", en Perspectivas de una España democrática y constitucionalizada, Madrid, Unión Editorial, 1979, vol. III, 428-29. La cursiva es del autor. Idéntico planteamiento asumieron las organizaciones patronales en 1931 al solicitar del Gobierno provisional la permanencia del ordenamiento jurídico vigente hasta que las Cortes Constituyentes y sólo ellas elaboraran la nueva normativa. CABRERA, Mercedes, La patronal ante la II República, p. 254.

14. La relación entre poder político y poder económico ha dado lugar a interpretaciones contrapuestas. Un estado de la cuestión sobre la defensa de los intereses organizados, en BERGER, Suzanne, "Introducción», en BERGER, Suzanne (comp.), La organización de los grupos de interés en Europa occidental, Madrid, Ministerio de Trabajo y Seguridad Social, 1988, pp. 13-39 y MAIER, Charles S., "Los vínculos ficticios de la riqueza y de la ley: sobre la teoría y la práctica de la representación de los intereses", en Ibidem, pp. 43-85. Para España y el período de la Restauración, véase PiQUerAS ARENAS, José A., "Negocios y política en el siglo XIX español», pp. 11-29. También CRUZ ARTACHO, Salvador, "Oligarquía y caciquismo", pp. 43-47. 
adecuados si desean conservar el apoyo de la sociedad y mantenerse en el poder. Es indudable que, con esa misma finalidad, deben redistribuir de forma más o menos equilibrada los beneficios de tal crecimiento entre los distintos intereses, aunque como es lógico tenderán a favorecer aquellos sectores del electorado que puedan incrementar la probabilidad de mantenerse en el poder. Aún así, resulta meridianamente claro que, en una economía de libre mercado, el crecimiento proviene básicamente de la actividad empresarial. En suma, los empresarios no son un grupo de interés como cualquier otro dada su estratégica posición en una economía capitalista.

Conforme a los planteamientos formulados, no puede deducirse que los empresarios, en cuanto tales, rechacen la democracia pero su aceptación no es incondicional. Debe tratarse de una democracia vinculada a la economía de libre mercado -aunque lógicamente comprometida con la protección de los intereses de la economía nacional-, capaz de garantizar la estabilidad política, el orden público y la propiedad privada. Elementos que no implican una oposición a objetivos redistributivos de la prosperidad, siempre y cuando se hallen condicionados al respeto y defensa de sus intereses, que suelen ser identificados con el interés general de la Nación.

En definitiva, la necesidad imperiosa de seguridad en sus expectativas de negocio contribuye a explicar su actitud en aquellos períodos en los que perciben vulnerabilidad en los poderes públicos y no se hallan en condiciones de tutelar con eficacia sus intereses. Esas coyunturas, en las que la instrumentalización recíproca que caracteriza sus relaciones ya no se desarrolla de modo adecuado o, cuando menos, no satisface las expectativas de los empresarios, suscitan una especial sensibilización hacia la gestión política. Determinados sectores, los más perjudicados o inquietos por ese mal funcionamiento, se mostrarán favorables e incluso apoyarán el cambio político. Pero las simpatías serán escasas o nulas entre aquellos en los que la actuación de los gobiernos no suscite inseguridad y desconfianza. Por otra parte, tanto en un caso como en otro influirán motivaciones de tipo ideológico y político puesto que la actuación de los empresarios no siempre obedece a cálculos racionales.

Así pues, tanto en vísperas de la II República como en los últimos años del régimen franquista no pocos sectores empresariales anhelaban un cambio que pusiera fin a la desconfianza y a la incertidumbre generada por la debilidad del régimen anterior. Paradójicamente, un cambio de esa naturaleza no acaba con la inseguridad; por el contrario, la fase de transición suele intensificarla ante la inexistencia de un marco institucional claro y perfectamente definido. La desconfianza en el futuro, en su propio futuro como empresarios, se instala con redoblada fuerza y el resultado inevitable, "normal» en esos momentos, consiste en la fuga de capitales y la contracción de las inversiones ${ }^{15}$. No obstante, la caí-

15. La inseguridad entre los empresarios ante la incertidumbre sobre el futuro político del país ya era notoria en 1930. PALAFOX, Jordi, Atraso económico y democracia. La Segunda República y la economía española, 1892-1936, Barcelona, Crítica, 1991, pp. 175-176. Lo de normal, en CABRERA, Mercedes, La patronal ante la II República, p. 253. Para los últimos años del franquismo, VV. 
da de la inversión productiva en los años 1931-1933 y 1974-1977 tuvo, además, unas motivaciones claras de orden económico. La gravedad de la crisis, unido al despliegue de una intensa presión sindical que forzó la concesión de importantes aumentos de salarios, sin correspondencia alguna con los de la productividad, provocó una sensible reducción de los excedentes empresariales, empeoró aún más sus expectativas y, por consiguiente, desanimó la inversión ${ }^{16}$.

Sin embargo, podría plantearse la presencia de una diferencia notable. En abril de 1931 accedieron al poder partidos políticos que pretendían modernizar el país aplicando un programa de reformas de tipo político, económico y social. En 1976, en cambio, ya no era precisa una reforma de dimensión global puesto que en el ámbito económico y social, la modernización -ciertamente limitada y lejos de los estándares europeos- ya era un hecho. No obstante, tanto en un caso como en otro, partidos y organizaciones que habían sido marginados -expulsados en el caso de la dictadura franquista- retornaron a la vida política para impugnar las relaciones de poder existentes. Y ese objetivo, evidentemente, no podía por menos de afectar a los empresarios y a sus intereses, máxime cuando era compartido por amplias capas de la sociedad, entre las que se hallaba muy extendida una imagen negativa, incluso francamente hostil, del empresario al que se catalogaba como capitalista explotador de los trabajadores ${ }^{17}$.

Temor al presente e incertidumbre en el futuro, pero en ninguno de ambos casos hubo oposición al cambio político. Claras simpatías en algunos sectores, actitud de espera en otros $y$, en general, la constatación de que era necesario adaptarse a la nueva situación, aunque, como es lógico, tampoco estuvo ausente el recelo y la desconfianza. En todo caso, prevalecieron las muestras de reconocimiento y apoyo a los poderes constituidos, aunque acompañados de la petición insistente de prudencia y moderación, respeto a la ley y, sobre todo, a la economía de mercado y a la libertad de iniciativa empresarial ${ }^{18}$.

AA., Economía española: 1960-1980. Crecimiento y cambio estructural, H. Blume Ed., 1983, p. 33; GONZÁLEZ FERNÁNDEZ, Ángeles, «Los empresarios ante los cambios económicos y sociales», en SÁNCHEZ RECIO, Glicerio (coord.), Eppure si muove. La percepción de los cambios en España (19591973), Madrid, Biblioteca Nueva, 2007, pp. 101-119.

16. Cfr. CARRERAS, Albert, "Gasto nacional bruto y formación de capital en España, 1849-1958: primer ensayo de estimación", en MARTín ACEÑA, Pablo y PrADOS, Leandro (eds.), La nueva historia económica de España, Madrid, Tecnos, 1985, pp. 17-51 y 43; PALAFOX, Jordi, Atraso económico y democracia, pp. 181-184. Para el período 1974 y 1977, VV. AA., Economía española: 1960-1980, pp. 242-245.

17. "A los patronos se nos persigue como a fieras», cit. en JuliÁ, Santos, Madrid, 1931-1934. De la fiesta popular a la lucha de clases, Madrid, Siglo XXI, 1984, p. 290. El desarrollo de una cultura anticapitalista en los sesenta y setenta. en CABRERA, Mercedes y ReY REGUILLO, Fernando del, El poder de los empresarios. Política y economía en la España contemporánea (1875-2000), Madrid, Santillana Ed., 2002, pp. 328-330; GonZÁLEZ FERNÁNDEZ, Ángeles, «Los empresarios ante los cambios económicos y sociales", p. 118.

18. CABRERA, Mercedes, La patronal ante la II República, aunque subraya que las entidades agrarias no manifestaron expresamente su aceptación del nuevo régimen, p. 253 y 283. JULIÁ, Santos, Madrid, 1931-1934, pp. 15, 30 y ss.; BENGOECHEA, Soledad, Reacció en temps de canvis, pp. 2527. "En suma, se trata de ser sensibles a los problemas que determinan el radical cambio que estamos teniendo, intentando comprenderlos y ayudando a solucionarlos. Oponiéndonos, no 
Principios básicos e irrenunciables a los que, además, se añadió otro elemento no menos importante, derivado de la situación económica. Los empresarios no cuestionaron la necesidad de reformas, tanto políticas como en el ámbito de las relaciones laborales. Incluso mostraron cierta comprensión hacia éstas, si bien limitada a los incrementos salariales que paliaran los efectos de la crisis entre los trabajadores. No obstante, la cuestión primordial -a su juicio- radicaba en la superación de la crisis económica. A ese objetivo debían supeditarse los cambios o -cuando menos habían de implementarse de manera paralela ${ }^{19}$.

Éste es uno de los elementos fundamentales que explican su insistencia en la necesidad del consenso para la elaboración y ejecución de las reformas ${ }^{20}$. Un acuerdo que obviamente correspondía a los actores políticos. Conforme a su aceptación del nuevo régimen, los empresarios reconocieron de modo explícito la legitimidad del ejecutivo para elaborar y aplicar la política económica, lo que no impidió que advirtieran sobre los riesgos que conllevaría una pérdida de la confianza empresarial sobre la inversión y, en definitiva, sobre el propio Gobierno ${ }^{21}$. Por ello, preconizaron la necesidad de que las reformas de carácter económico y del marco de relaciones laborales, se efectuaran de manera consensuada y con el concurso de los empresarios. Una colaboración conveniente y necesaria por tres motivaciones fundamentales. La primera tenía su razón de ser en el hecho de que a los empresarios correspondía su ejecución y, por tanto, no podían ser aplicadas sin un proceso previo de consulta y negociación. La segunda se apoyaba en la convicción de que -por su conocimiento directo de la realidad económica y, por supuesto, de la empresa- eran los más capacitados para elaborar la receta -el programa económico- que permitiría solventar la crisis. Por último e íntimamente relacionada con la anterior, en el ánimo de los empresarios influyó sobremanera la presencia de una muy pobre opinión sobre los políticos, sobre su competencia y sensatez para afrontar con decisión los

los impediremos. E ignorándolos, no los evitaremos», Santiago Foncillas, presidente del Círculo de Empresarios, El País, 21-11-1979.

19. GONZÁLEZ FERNÁNDEZ, Ángeles, «El empresariado en tiempo de cambios. Negocios, poder y política en la transición a la democracia», Alcores (en prensa).

20. CABRERA, Mercedes, La patronal ante la II República, p. 6. Así, por ejemplo, el empresario catalán Pedro Durán Farrell abogó por el establecimiento de un pacto político considerado como un paso previo para un posterior pacto social, en el que deberían participar el PCE y Comisiones Obreras, El País, 18-7-1976.

21. "Nos apresuramos a dar ejemplo asegurando una vez más nuestro respeto a cuantas disposiciones emanen legalmente del poder constituido». Nota firmada por más de 300 organizaciones patronales en junio de 1931. Cit. en CABRERA, Mercedes, La patronal ante la II República, p. 254. «Por supuesto, que nuestra actitud no va a ser, a partir de ahora, la de no pagar impuestos o dedicarnos al obstruccionismo. Lo que pasa es que puede perderse la confianza empresarial en la política económica del Gobierno, y la economía, indudablemente, se resentirá. Donde no hay confianza no hay inversión". "Ahí está el programa económico y debemos aceptarlo como se ha hecho tradicionalmente. Unos hacen las leyes y los otros tienen que obedecerlas». FERRER SALAT, C., cit. en GONZÁLEZ FERNÁNDEZ, Ángeles, "El empresariado en tiempo de cambios», Alcores (en prensa). 
problemas económicos que, en su opinión, requerían una atención prioritaria y urgente.

Esta fue una reclamación constante que, sin embargo, no obtuvo la respuesta esperada. La prioridad otorgada a la solución del problema social en el bienio reformista y, en los años setenta, hacia la reforma política, postergó la adopción de medidas que afrontaran la crisis, agravado en el caso de los años treinta por la notoria despreocupación hacia las repercusiones económicas de la nueva legislación. La actuación del Gobierno provisional en 1931 tanto como la de los primeros gobiernos de la monarquía estuvo marcada por una notoria preocupación social en el ámbito de las relaciones laborales, basada en una concepción similar de la empresa que enfatizaba su función social en detrimento de su función económica.

Indudablemente los planteamientos y objetivos en ambos períodos eran sustancialmente diferentes. A pesar de que el programa de gobierno en los años 1931-33 no era socialista, la búsqueda de colaboración y apoyo de los agentes sociales fue, en todo caso, más discursiva que real en lo que se refiere a los «capitalistas». Sobre ellos, en realidad, recaían los mayores sacrificios en la aplicación del programa reformador ${ }^{22}$. En cambio, la declaración programática del gobierno Suárez tras las elecciones de junio de 1977 afirmaba su voluntad de obtener "la colaboración responsable de todos los grupos sociales y partidos políticos» para abordar la solución de los graves desequilibrios económicos mediante la aplicación de un proceso de ajuste ${ }^{23}$. Y desde luego los empresarios se acogieron a esa declaración para insistir en la necesidad de un gran pacto social «en virtud del cual cada uno acepta una parte del coste que inevitablemente habrá de pagar para reducir la inflación y colocar a la economía en la senda de un crecimiento sano» ${ }^{24}$.

Fiel reflejo de esta posición fue la tentativa de su Gobierno de pactar con los agentes sociales el programa de ajuste económico en el verano de 1977. Las negociaciones no llegaron a buen puerto debido a la divergencia de posturas entre las tres partes y a la débil institucionalización de las organizaciones sindicales y empresariales, pero no hubo nada parecido en 1931. Los Pactos de la Moncloa, firmados por los partidos políticos con representación parlamentaria, fueron mal acogidos por los dirigentes de la CEOE, precisamente por su exclusión

22. "Reclamamos el apoyo de todos; no rechazamos el auxilio de nadie. Pedimos, y pedimos clamantes, el de todas, porque es obra de reconstrucción, de sacrificio para todos y principalmente debe serlo para las clases capitalistas del país». I. Prieto en las Cortes, cit. en VIDARTE, Juan Simeón, Las Cortes Constituyentes de 1931-1933, p. 107. El mismo Prieto realizó unas declaraciones en las que amenazaba a los propietarios de capital con intervenir y bloquear sus cuentas corrientes, que lógicamente, acentuaron la desconfianza. VeNTOSA CALVELL, J., La situación política y los problemas económicos de España, Barcelona, 1932, p. 157.

23. El País, 11-7-1977.

24. Declaraciones de A. Ribera Rovira, presidente de la Cámara de Comercio de Barcelona. En el mismo sentido se expresó C. Ferrer Salat en julio de 1977, cit. en TRULlen I THOMAS, J., Fundamentos económicos de la transición política española. La política económica de los Acuerdos de la Moncloa, Madrid, 1993, pp. 158-160. 
aunque también por su contenido, que juzgaban demasiado tímido. Sus críticas, sin embargo, pronto se trocaron en una aceptación resignada porque, pese a la ausencia de las cuestiones más caras al empresariado (libertad de negociación, flexibilización de plantillas, absentismo, productividad y reforma de la financiación de la seguridad social), introducía la moderación salarial como mecanismo para combatir la inflación y el déficit público.

En el mismo sentido, los respectivos textos constituyentes presentan sensibles diferencias. Se ha subrayado que la Carta Magna de 1931 fue el referente en 1978, pero -tal como afirma J. Corcuera ${ }^{25}$ - muchas de las influencias que pudieran plantearse entre una y otra son más aparentes que reales puesto que los rasgos fundamentales de la Constitución de 1978 derivan de las características del constitucionalismo de finales del siglo XX. Desde luego una diferencia sustancial, y no menor, residió en el hecho de que el texto de 1931 no fue resultado de un consenso que permitiera a las derechas -y en el caso que nos ocupa a los empresarios- sentirse parte integrante del nuevo régimen. Todo lo contrario, la oferta de "la más leal y sincera colaboración» formulada a las Cortes Constituyentes por las entidades económicas y patronales fue desatendida de un modo que no deja lugar a dudas.

La misma definición de España como «una República democrática de trabajadores de toda clase» en su artículo $1 .^{\circ}$ puso de manifiesto que se trataba de una democracia formada por una comunidad de trabajadores en la que sólo con un considerable esfuerzo los empresarios podían sentirse incluidos. De otro lado y al igual que otras constituciones de la época, el texto introdujo una redefinición del concepto de propiedad en la medida que el Estado asumió una función de especial protección de los derechos de determinados colectivos y, en consecuencia, una actuación directa en la estructura económica. Es cierto que se reconocía el derecho de propiedad, pero se trataba de una "propiedad muy condicionada» entre otras cuestiones porque, pese a que contemplaba la socialización como una posibilidad y no como una imposición, el artículo 44 parecía sustentarse en la futura consecución de una sociedad socialista que negaba la posibilidad de que la iniciativa individual pudiera llevar a cabo actividades beneficiosas para el bien común. En suma, el espíritu y la letra de la nueva Constitución incrementaron la desconfianza e inseguridad de los empresarios hacia una República en la que sus intereses no parecían tener acomodo ${ }^{26}$.

Al igual que en 1931, la Constitución de 1978 subordina la riqueza del país a los intereses de la economía nacional en el marco de una economía social de

25. CORCUERA ATIENZA, Javier, "La constitución española de 1931 en la historia constitucional comparada", Fundamentos. Cuadernos monográficos de teoría del Estado, derecho público e historia constitucional, n..$^{\circ}$ (2000), pp. 629-695.

26. CORCUERA ATIENZA, Javier, "La constitución española de 1931 en la historia constitucional comparada», pp. 629-695; "El constitucionalismo de entreguerras y la Constitución española de 1931", Historia Contemporánea, n. 6 (1991), p. 28; MEER, Fernando de, La constitución de la II República, Pamplona, Eunsa, 1978; GARRIDO GONZÁLEZ, Luis, "Constitución y reformas socioeconómicas en la España de la II República», Ibidem, p. 173. 
mercado, pero al mismo tiempo proclama de manera clara la libertad de empresa en su artículo 38 y en ningún caso contempla la posibilidad de expropiación sin indemnización como en 1931. En otras palabras, la actual Constitución establece un sistema de economía mixta, semejante al que está en vigor en los países de Europa occidental desde el final de la Segunda Guerra Mundial. Un sistema que descansa en el derecho de propiedad privada y la libertad de empresa como elementos clave en una economía de libre mercado, aunque otorga al sector público cierta capacidad de actuación con fines distributivos, estabilizadores y de orientación general de la actividad económica ${ }^{27}$.

Cabe subrayar, además, que con posterioridad a la aprobación de la Constitución, se dictaron una serie de normas que fijaban la representatividad como criterio para seleccionar un reducido número de interlocutores sociales, a los que se otorgaba un tratamiento legal privilegiado. En otras palabras, las posibilidades de acción, gran parte de las vías de financiación y, también su status ante los poderes públicos estaba en función del índice de representatividad de las organizaciones tanto empresariales como sindicales. Este sistema contribuyó a la consolidación de la CEOE, de las organizaciones sindicales mayoritarias (CC. O०. y UGT) y facilitó el proceso de concertación social ${ }^{28}$.

Por último, no está de más señalar las tentativas de establecer una segunda cámara representativa de los intereses organizados. Propuesta incluida en el anteproyecto de Constitución elaborado en 1931 por la comisión jurídica asesora. Contemplada también en el proyecto de reforma política de Arias-Fraga y, de forma parcial, en el proyecto de reforma redactado por T. Fernández Miranda. En el primer caso, la iniciativa no salió adelante al no encontrar apoyo en los partidos que formaban el Gobierno; en el segundo, al ser descartada en el texto final del proyecto de ley para la reforma política. Por lo que se refiere a la reacción de los empresarios ante tal fórmula, a lo largo del período republicano diversas organizaciones mostraron su apoyo a la creación de un senado corporativo que actuara como freno a las iniciativas de la cámara baja. Durante la transición a la democracia, en cambio, hubo un claro distanciamiento de los sectores mayoritarios, aunque los círculos inmovilistas aplaudieron la propuesta y la defendieron con especial denuedo en las Cortes $^{29}$.

27. SeRRANO SANZ, José María, "Crisis económica y transición política», en REDERO SAN ROMÁN, Manuel, La transición a la democracia, p. 152.

28. GARCÍA MURCIA, Javier, Organizaciones sindicales y empresariales más representativas. Posición jurídica y dimensión política, Madrid, Ministerio de Trabajo y Seguridad Social, 1987; GALÁn GARCíA, Agustín y RODRíGUEZ-PIÑERO ROYO, Miguel, «El marco legal y las leyes laborales durante la transición", en ÁLVAREZ ReY, Leandro y LEMUS LÓPEZ, Encarnación (coords.), Sindicatos y trabajadores en Sevilla, Sevilla, Universidad-Fundación El Monte, 2000, p. 375.

29. El malestar de Fomento del Trabajo Nacional por su exclusión del texto constituyente, en BENGOECHEA, Soledad, Reacció en temps de canvis, p. 26. La postura favorable de Unión Económica en 1934, en CABRERA, Mercedes, La patronal ante la II República, p. 265. Para la transición, GONZÁLEZ FERNÁNDEZ, Ángeles, «El Consejo Nacional de Empresarios ante el proceso de reforma política», en QuirosA-ChEYROUZe, Rafael (coord.), Historia de la Transición en España. Los inicios del proceso democratizador, Madrid, Biblioteca Nueva, 2007. 


\section{LOS EMPRESARIOS Y LOS PARTIDOS POLÍTICOS}

Los empresarios y sus organizaciones suelen definirse en sus estatutos como apolíticas. Una afirmación que no es enteramente correcta porque los empresarios se identifican con un modelo socioeconómico muy concreto que los emplaza en una posición política determinada. Del mismo modo, tampoco son apartidistas ya que tienden a identificarse con aquellas formaciones que, a priori, se muestran más afines a sus intereses. No obstante, dado que pretenden situarse y permanecer en las proximidades de los ámbitos de decisión política, intentarán mantener contactos fluidos con los poderes públicos, sea cual sea su ideología ${ }^{30}$.

En cualquier caso, los empresarios ambicionan disponer de un partido que opere como transmisor y defensor de sus intereses desde el poder o, al menos, desde la oposición parlamentaria, especialmente en los procesos de cambio político. En realidad, ésta es una pretensión imposible puesto que ninguna formación política, con vocación de formar gobierno por supuesto, puede asumir por entero los intereses de un determinado grupo. Ciertamente, en la II República no pocos empresarios engrosaron las filas del Partido Radical en la consideración de que constituía el mejor valladar contra el socialismo. No obstante, nunca fue el partido de los patronos tanto por la heterogeneidad de su base social como por su voluntad de mantener las simpatías y los votos de sus seguidores entre las clases trabajadoras ${ }^{31}$. Tampoco lo fue la CEDA. Ciertamente, bajo sus siglas se cobijaron desde los pequeños propietarios rurales castellanos, terratenientes andaluces y propietarios agrarios levantinos hasta destacadas personalidades de las finanzas confiados todos ellos en su capacidad para rectificar la República. Del mismo modo, su programa contenía puntos coincidentes con los defendidos por los patronos, especialmente la defensa de la propiedad privada como columna vertebral del orden "natural» capitalista. Sin embargo, otros puntos de su programa como el reformismo social, inspirado en la doctrina social católica, los planteamientos corporativistas y el dirigismo económico, suscitaron desagrado y rechazo entre no pocos sectores empresariales ${ }^{32}$.

Afirmación similar puede hacerse para los años de la Transición. Por lo que se refiere a UCD, en vísperas de las elecciones de 1977 parecía ser la formación

30. Así, por ejemplo, los dirigentes de Fomento del Trabajo Nacional afirmaron que siempre habían sido gubernamentales con cualquier régimen y con todos los gobiernos. BENGOECHEA, Soledad, Reacció en temps de canvis, p. 26. GONZÁLEZ FERNÁNDEZ, Ángeles, "De la neutralidad a la beligerancia: empresarios y elecciones en la transición a la democracia", en RAMOS SANTANA, Alberto (coord.), La Transición: política y sociedad en Andalucia, Cádiz, Ayuntamiento de Cádiz, 2005, p. 199.

31. Tras las elecciones generales de junio de 1931, «toda España ha vuelto los ojos hacia el ídolo radical. Los banqueros, los grandes comerciantes e industriales, la gente de buena casa, se hacen radicales». Pla, Josep, "El advenimiento de la República», en PERICAY, Xavier (ed.), Cuatro historias de la República, Madrid, Ed. Destino, 2003, p. 154. Cfr. TownSON, Nigel, La República que no pudo ser. La política de centro en España, Madrid, Santillana, 2002, pp. 135, 138 y 154-155.

32. Un análisis de su base social, concepto de propiedad privada y reformismo social, en MONTERO, José R., La CEDA. El catolicismo social y político en la II República, Madrid, Ed. de la Revista de Trabajo, 1977. 
política que mayores garantías podía ofrecer al mundo empresarial a la hora de proporcionar estabilidad a la vida política, evitar el triunfo de las izquierdas y proteger adecuadamente a la empresa. Sin embargo, en ningún momento el partido asumió los intereses de los empresarios como propios dada su condición de partido catch-all; por el contrario, su labor de gobierno generó un claro distanciamiento y no poca hostilidad en la consideración de que practicaba una política de izquierda con los votos de la derecha y, más grave aún, una «vertiginosa socialización de la economía ${ }^{33}$.

Como afirma L. Lanzalaco, no siempre los gobiernos considerados más próximos a las posiciones de los empresarios llevan a cabo las políticas más coherentes con la lógica de mercado por razones de carácter electoral y político. "La paradoja de los gobiernos amigos» tuvo una fiel traslación en lo que se refiere a la CEDA -aunque no en lo relativo a los propietarios agrarios, su base electoral por excelencia, aspecto que, por otro lado, agudizó el descontento entre industriales y comerciantes. Y también contribuye a explicar las difíciles relaciones entre la CEOE y UCD, debido a que la trayectoria de los gobiernos de este partido estuvo condicionada por el continuo temor a un trasvase de votos hacia el $\mathrm{PSOE}^{34}$. En consecuencia, tanto la labor de gobierno de los radicalcedistas en 1933-1936 como de la UCD en el período 1976-1982 provocaron frustración y desengaño.

En cuanto a Alianza Popular, el partido ofreció una imagen excesivamente derechista tanto por la personalidad y discurso de sus principales dirigentes como por su propia estructura como partido de clientela. Una formación que pretendía mantener en lo esencial el régimen franquista $y$, por tanto, muy alejado de las expectativas de la mayor parte del electorado y, también, de buena parte de los empresarios. Bien es verdad que AP contaba con un yacimiento de votos apreciable entre los pequeños y medianos propietarios agrarios, pero precisamente por su conexión con el franquismo y, por extensión, con su política económica, no podía constituirse en representante de aquellos sectores que deseaban la introducción de una economía de libre mercado ${ }^{35}$. Por otro lado, sus desastrosos resultados en las legislativas de 1977 restaron credibilidad al partido no sólo como alternativa de poder sino incluso como transmisor de sus intereses en el parlamento. No obstante, el malestar de los empresarios hacia el partido en el Gobierno provocó que a comienzos de 1978 diversos dirigentes

33. Ante los requerimientos de la federación empresarial granadina, la dirección provincial del partido se mostró contundente: «UCD es un partido interclasista. Nosotros escuchamos a todo el mundo que quiera plantearnos un problema y apoyamos cualquier petición que consideremos justa, sea del sector que sea», Ideal de Granada, 1-4-1978.

34. LANZALACO, Luca y URBANI, Giuliano, Imprenditori in Europa. Le rappresentanze imprenditoriali in prospettiva comparata, Roma, SPI, 1992, p. 20. De hecho, la CEDA no puede ser considerada representativa de los sectores industriales. CABRERA, Mercedes, La patronal ante la II República, pp. 19-20. GONZÁlEZ FeRnÁNDEZ, Ángeles, «Los empresarios en tiempo de cambios. Negocios, poder y política en la transición a la democracia", Alcores (en prensa).

35. Sobre AP, véase LÓPEZ NIETO, Lourdes, Alianza Popular: estructura y evolución electoral de un partido conservador, Madrid, CIS, 1988. 
empresariales intentaran un acercamiento que resultó decepcionante. M. Fraga afirmó su disposición a actuar en defensa de sus intereses pero «sin condiciones y sin compromiso", puesto que "AP no es un partido de clase» ${ }^{36}$.

Por último, la postura del empresariado en relación al PSOE presenta algunas diferencias y no pocas similitudes, derivadas en gran medida de las propias actitudes y discurso del partido hacia los empresarios y de su dispar posición política: integrante de la coalición de gobierno en el bienio 1931-33, principal partido de la oposición en 1977-1982. Aunque como ya se ha advertido, en los años treinta el PSOE no pretendió aplicar un programa de gobierno socialista, las declaraciones de los principales dirigentes del partido y de la UGT no dejaban lugar a dudas sobre su concepción de la República como paso intermedio hacia una sociedad socialista. Interludio necesario que, como tal, era preciso consolidar pero con la mirada siempre en el futuro, un futuro que advendría paulatinamente y sin violencia pero de modo inexorable.

Así lo manifestó Fernando de los Ríos en junio de 1931: «la función del PSOE consiste en "sostener la democracia política e ir realizando una ordenación socialista de la economía». Una función que, para los empresarios, Largo Caballero había emprendido desde el Ministerio. Podría argüirse que las medidas del Ministro de Trabajo no tenían carácter revolucionario y se insertaban dentro de la corriente de pensamiento asentada en diversos regímenes de la época, pero su violencia verbal en la defensa de las reformas sociales y la imprudencia de sus declaraciones -llegó a anteponer su condición de líder de UGT a su función ministerial-contribuyeron a alimentar una imagen revolucionaria que, además, pareció ser de su agrado.

Para los empresarios no había duda alguna: la participación del PSOE en el Gobierno había operado una radical transformación del Estado, convertido en ejecutor de una política socialista, causa de todos los males económicos, políticos y sociales del país y para la que el Gobierno carecía de mandato constitucional. En consonancia, su salida del Gobierno pasó a ser una demanda constante en la consideración de que era el único medio de republicanizar la República y, naturalmente, salvar el país de la ruina ${ }^{37}$.

En los inicios de la transición a la democracia, el discurso oficial del partido mostraba una clara línea de continuidad con los años treinta. Así parece inferirse de su definición como partido marxista de clase y de los objetivos fijados en su XXVII congreso: "la conquista del poder político por la clase trabajadora y la transformación de la sociedad capitalista en una sociedad socialista». Sin embargo, Felipe González contribuyó de manera decisiva a la política de consenso y adoptó un lenguaje pragmático y moderado que contrastaba con el maximalismo del programa y las declaraciones de otros dirigentes. Así, por ejemplo, las

36. Ideal de Granada, 2-4-1978.

37. La cita de F. de los Ríos, en BizCARRONDO, Marta, "En torno a un viejo tema: "reforma» $y$ «revolución» en el socialismo de la Segunda República», en GARCÍA DELGADO, José Luis (ed.), La II República española. El primer bienio, Madrid, Siglo XXI, 1987, p. 53. FUENTES, Juan Francisco, Largo Caballero, el Lenin español, Madrid, Síntesis, 2005, pp. 210-211. 
propuestas para nacionalizar determinados sectores como la siderurgia, fueron acompañadas por reiterados intentos para tranquilizar a los empresarios ${ }^{38}$.

Sin embargo, la ambigüedad calculada y la falta de coherencia se convirtieron en los rasgos visibles del discurso socialista a lo largo de los años siguientes, de manera que las declaraciones de F. González en las que descartaba cualquier intencionalidad de estatalizar la economía no aminoraron el temor de los empresarios a su posible acceso al poder. Un temor que no desapareció tras la renuncia del partido al marxismo en 1979, que fue considerada desde fuentes empresariales como una simple "careta» con la finalidad de ocultar al electorado sus verdaderos propósitos. Sin embargo, el avance electoral logrado en las elecciones de ese año, en las que UCD tan sólo aventajó al PSOE en 800.000 votos, no provocó reacciones destempladas. Por el contrario, los dirigentes de la CEOE transmitieron un mensaje de tranquilidad y prudencia, justificado en la esperanza de que los exiguos resultados del partido en el Gobierno dieran lugar a una rectificación de su política y, sobre todo, al hecho de que el modelo social y económico ya estaba perfectamente definido en el texto constituyente ${ }^{39}$.

Así pues, los empresarios carecieron de una formación política que se identificara con sus intereses. Bien es verdad que no pocos empresarios militaban en las filas de los partidos de centro y derecha y que algunos de ellos ocuparon cargos políticos relevantes, incluso a nivel de gobierno. Pero el desempeño de estos puestos no otorgó a los empresarios en cuanto tales una influencia determinante en la política económica ${ }^{40}$.

\section{LA ACCIÓN COLECTIVA COMO ARMA DE PRESIÓN}

La legitimidad de cualquier sistema representativo depende de que los diversos intereses existentes en la sociedad se hallen adecuadamente representados. En caso de que así no suceda, si se cercenan las posibilidades de influir sobre la gestión política o perciban que sus intereses no son tutelados de manera eficaz, los empresarios -como cualquier otro grupo de interés- suelen adoptar actitudes de oposición. Inicialmente, pretenderán reconducir la labor del Gobierno mediante la puesta en práctica del repertorio de acción colectiva que les es propio. La persuasión, la intimidación y la corrupción serán aplicadas en

38. «La economía de mercado ni la defendemos, ni la atacamos, simplemente la aceptamos (...) Si los socialistas acceden en un futuro, más o menos mediato, al Gobierno, negociarán con todas aquellas fuerzas entre las que es previsible no cuenten con un amplio consenso; incluidos, por supuesto, los empresarios. Pero no les pediremos permiso para gobernar», GONZÁLEZ, Felipe, El País, 8-12-1977. "Hay un malentendido que debe aclararse, y es que en una perspectiva socialista también necesitamos empresarios; no queremos una economía de funcionarios, y pensamos que este papel del empresario socialista es clave en la transformación de la sociedad», BARÓN, Enrique, El País, 25-2-1978

39. GONZÁlEZ FeRnÁNDEZ, Ángeles, "Los empresarios en tiempo de cambios» (en prensa).

40. Por ejemplo, el secretario de la Confederación Gremial Española, el radical M. Marraco fue ministro de Hacienda desde 1933. A. Rodríguez Sahagún, uno de los padres fundadores de la CEOE y luego de CEPYME, ministro de Industria desde abril de 1978. 
sus distintas modalidades, de forma sucesiva o simultánea, para presionar a los gobiernos, la Administración, los partidos políticos y al electorado. Sólo en el caso de que la presión fracase, los empresarios, cuyo objetivo primordial como grupo de interés consiste en influir sobre el poder y no derribarlo, pueden adoptar estrategias conducentes a demoler un sistema político al que han llegado a considerar ilegítimo, precisamente porque ha perdido su carácter verdaderamente representativo.

Sin embargo, los empresarios -siempre necesitados de horizontes seguros y estables para sus negocios - sólo adoptarán esa solución como último recurso. Antes de llegar a ese extremo intentarán lograr una rectificación de la labor de gobierno que, naturalmente, se justifica en la defensa de los auténticos intereses de la Nación, postergados por intereses partidarios. Tanto en 1931 como en 1976 y a lo largo de los años siguientes, la creciente inquietud ante la evolución de los acontecimientos impulsó el recurso a los mecanismos a su alcance para conseguir esa corrección, pero en ningún caso pretendieron restablecer la situación anterior sino asegurar el respeto y defensa de sus intereses, que juzgaban desamparados cuando no directamente amenazados. Así pues, la actuación de los empresarios se realizó dentro de los límites establecidos por la democracia y conforme al repertorio de acción habitual de los grupos de interés. Las entrevistas con los jefes de gobierno, ministros y parlamentarios se complementaron con la publicación de informes, notas y manifiestos, campañas de prensa, asambleas y concentraciones. Acciones que, además, pretendían atraer las simpatías y comprensión del electorado y les proporcionaron un extraordinario protagonismo público y un papel político de primer orden.

Aunque, como ya se ha mencionado, las tentativas para crear una organización unitaria durante el período republicano fracasaron, a partir del 14 de abril se produjo un sensible incremento de las asociaciones patronales y la reorganización de las ya existentes. Así pues, esa misma primavera todos los sectores de la producción contaban con entidades representativas, si bien bajo el signo de la fragmentación tanto a nivel sectorial como territorial. No obstante, la dispersión organizativa -rasgo que también caracterizó el panorama asociativo empresarial de los primeros momentos de la Transición hasta la constitución formal de la CEOE, a finales de junio de $1977^{41}$ - no impidió una actuación conjunta que potenciara su representatividad y, por tanto, su capacidad de interlocución con el Gobierno. La acción colectiva, en consecuencia, pretendía el establecimiento de cauces de consulta y negociación sobre todas aquellas medidas legales que concernieran a la empresa y a los empresarios y, al mismo tiempo, persuadir

41. CABreRA, Mercedes, La patronal ante la II República, pp. 29-79. AGUILAR, Salvador, «El asociacionismo empresarial en la transición postfranquista", Papers, n. 24 (1985), pp. 53-84; GUTIÉRREZ ÁLVAREZ, Secundino J., Aproximación histórica a las organizaciones empresariales en España. II. Las organizaciones empresariales en la Transición: 1975-1978, Madrid, Fundación CEIM, 2001; GONZÁLEZ FERNÁNDEZ, Ángeles, «El mundo no empieza hoy ni partimos de la nada», pp. 271-288. 
a la opinión pública acerca de su papel fundamental como agente creador de riqueza y prosperidad general ${ }^{42}$.

La primera actuación de las organizaciones empresariales consistió en la traslación a los nuevos poderes de su malestar ante la gravedad de la crisis económica, la desbordada conflictividad laboral y las medidas adoptadas en el marco de relaciones laborales, acompañada, como es obvio, de sus propios planteamientos y propuestas. En agosto de 1931 diversas organizaciones patronales acordaron transmitir a las Cortes Constituyentes lo que podría considerarse como su propio programa de política económica e idéntico proceder llevó a cabo la CEOE en el verano de 1977. Como es natural, ambos presentan diferencias notables, puesto que el papel económico del Estado y la situación de los propios empresarios también lo eran, pero el planteamiento globalmente considerado puede considerarse similar.

Tomemos como ejemplo el déficit público. Motivado por causas claramente distintas, como también lo era su composición, la actitud de los empresarios fue, en esencia, la misma. En el primer caso, pese a que compartían con los poderes públicos la necesidad de un equilibrio presupuestario, convenían en subrayar que la gravedad de la situación económica requería la aplicación de una política expansiva del gasto público -y, por tanto, un aumento del déficit- para compensar la reducción de la iniciativa privada en los sectores en crisis y reactivar al conjunto de la economía. Cuarenta años después, los dirigentes de la CEOE reclamaron con insistencia la reducción del gasto público pero, al mismo tiempo y entre otras, la libertad de contratación y despido (luego matizada por el uso del término flexibilización), una mayor participación del Estado en los gastos de la Seguridad Social y la reducción de los impuestos, cuestiones todas que implicaban incrementos del déficit ${ }^{43}$. Una contradicción evidente que, sin embargo, no parecía ser tal para los empresarios, para los que la reducción de la deuda del Estado debía provenir de una contracción de los gastos no productivos y en ningún caso de sus obligaciones con la economía nacional.

Un paso más allá se produjo en el momento en que se pretendió establecer un nuevo marco de relaciones laborales y, en concreto, la participación de los trabajadores y de sus organizaciones en la gestión de las empresas. La presentación en Cortes del proyecto de ley de intervención obrera en la gestión de las industrias, conocido por los empresarios como de control obrero, en 1931, y de acción sindical en la empresa, a finales de 1977, provocó una respuesta unánime y contundente. En ambos momentos, los empresarios y sus organizaciones

42. CABRERA, Mercedes, Ibidem, p. 261. Prácticamente todos los estatutos de las asociaciones empresariales creadas a partir de 1976 estipulaban entre sus objetivos la mejora de la imagen pública del empresariado. A partir de 1979 la CEOE procedió a la creación de departamentos especializados en relaciones institucionales en la convicción de que "estamos ante una guerra de información, en la que los empresarios no pueden permitirse el lujo de perder las batallas diarias de la información", Boletín de la CEOE, marzo de 1979.

43. CABRERA, M., La patronal ante la II República, pp. 51 y 90. El programa económico de la CEOE, en GONZÁLEZ FERNÁNDEZ, A., «El empresariado en tiempo de cambios»; CALVO SOTELO, Leopoldo, Memoria viva de la transición, Barcelona, Plaza y Janés/Cambio 16, 1990, pp. 167-168. 
estimaron que se trataba de un intervencionismo abusivo del Estado y, más grave aún, de una iniciativa de clara orientación marxista, una agresión contra la libre empresa que significaría la muerte del empresario y, por consiguiente, la ruina del país ${ }^{44}$.

La petición de retirada del texto de las Cortes fue acompañada de presiones sobre los ministros y parlamentarios, el despliegue de una intensa campaña de prensa y la celebración de numerosas asambleas que pusieron de manifiesto la capacidad de convocatoria de sus organizaciones. No obstante, en 1931 no hubo una movilización similar a la desplegada en 1978 pero ello simplemente se debió a la paralización del proyecto de ley, que se estancó en la comisión parlamentaria. La campaña de la CEOE alcanzó su culminación precisamente durante los debates en el Pleno de las Cortes del anteproyecto, momentos en que la campaña se convirtió en una verdadera demostración del poder empresarial con la realización de concentraciones multitudinarias que consiguieron la modificación sustancial del texto.

Sin embargo, también en 1931 y a lo largo de los años siguientes, las organizaciones patronales recurrieron a la movilización de los empresarios contra la política gubernamental. Así sucedió en el mes de julio de ese año con el objetivo primordial de expresar su oposición a los jurados mixtos y en el verano de 1933, en el que la convocatoria de una «magna asamblea nacional» contó con la asistencia de «más de un millar de asociaciones patronales» que reclamaron, entre otras cuestiones, la reforma de los jurados. Sin embargo, existió una diferencia fundamental entre ambos procesos movilizadores, puesto que las discrepancias registradas en 1933 tanto sobre el modelo asociativo a crear como con respecto a la postura frente al Gobierno, no se produjeron en 1978. Por el contrario, los dirigentes de la CEOE y los 13.000 empresarios asistentes a la concentración celebrada a comienzos de ese año ofrecieron al Gobierno y a la opinión pública una imagen cohesionada que mostró los notables progresos alcanzados en la consolidación de la organización.

En cualquier caso, la respuesta de los gobiernos no fue la esperada. La profundización de la crisis económica y la agudización de la percepción de orfandad política, abrió el camino para la aparición de otras modalidades de acción, nacidas de la convicción de que debían operar en la vida política por sí mismos, sin intermediación de los partidos para la defensa de sus intereses. Durante el segundo bienio republicano se lanzaron diversas propuestas para la creación de un partido político patronal que reivindicara el papel de los patronos y defendiera sus intereses frente a los "profesionales de la política». Sin embargo, ninguna de estas iniciativas -surgidas de entre los pequeños y medianos empresarios- llegó a buen puerto debido a la existencia de intereses y actitudes

44. CABReRA, Mercedes, La patronal ante la II República, pp. 198-202. Argumento similar opusieron a la ley contra el paro, como una nueva intromisión en la gerencia privada de las industrias, Ibidem, p 248. GONZÁLEZ FERNÁNDEZ, Ángeles, «El empresariado en tiempo de cambios». Cabe subrayar las declaraciones de Aguirre Gonzalo, presidente de Banesto, «el Estado debe ser garante, no gerente, de la empresa privada", El País, 3-7-1979. 
contrapuestas y al recelo que despertaron entre los grandes empresarios. Pese a ello, revistieron suma importancia en cuanto los virulentos ataques a los actores políticos, incluidos los considerados en principio como transmisores de sus intereses, reflejaba la existencia de una profunda desconfianza hacia el sistema parlamentario aunque de ello no pueda deducirse apoyo a los partidos fascistas y a una salida de signo totalitario ${ }^{45}$.

Es cierto que también en los años de la transición a la democracia se atribuyeron a Ferrer Salat ambiciones políticas -negadas por el que fuera presidente de la CEOE-, pero no hubo propuestas para fundar un partido propio como tampoco desconfianza hacia el sistema parlamentario. En cambio, a partir de 1980 la falta de credibilidad en UCD, acentuada por su acelerado proceso de descomposición interna, y el temor a un triunfo electoral del PSOE, impulsó la promoción de un gran partido de centro-derecha, más proclive en teoría a los intereses empresariales. Así pues, a partir de 1980 la CEOE actuó como actor político, en abierta competencia con el partido en el Gobierno en las sucesivas contiendas electorales, tanto autonómicas como generales ${ }^{46}$. Pese a que no pudo evitar el acceso de los socialistas al poder, su estrategia contribuyó al hundimiento de UCD, a la consolidación de AP, que concurrió a las elecciones bajo la denominación de Coalición Popular y pasó a convertirse en el principal partido de la oposición. El fracaso a nivel político no lo fue, sin embargo, en el plano organizacional. Las campañas políticas operaron como factor de cohesión y movilización del empresariado, reforzaron el control de la CEOE sobre sus asociaciones miembro y, en consecuencia, consolidaron su condición de organización cúpula del sistema asociativo empresarial y, como tal, interlocutora única de los poderes públicos.

A modo de conclusión, podría afirmarse la existencia de un claro paralelismo en las actitudes y estrategias de los empresarios ante la II República y la transición a la democracia españolas. Y ello, pese a tratarse de dos modelos de cambio distintos y a la existencia de contextos políticos y económico-sociales diferentes, tanto a nivel nacional como internacional. Ese paralelismo es el resultado lógico de la propia actividad que desarrollan los empresarios, precisados y ávidos de un marco político sólido y estable que pueda garantizar seguridad en sus expectativas de negocios. La debilidad, inoperancia y/o parcialidad de los poderes públicos siempre generan incertidumbre y retraen la inversión, máxime si -como en el caso que nos ocupa- las crisis políticas del régimen de la Restauración y luego la del franquismo se desarrollan de manera simultánea

45. La iniciativa de crear un partido patronal que asumiera la defensa de sus intereses ante los poderes públicos al margen de toda mediación política ya había sido planteada por los patronos del comercio en 1930 aunque fue a partir de 1933 cuando se planteó de forma insistente. Juliá, Santos, Madrid, 1931-1934, p. 113. CABRERA, Mercedes, La patronal ante la II República, pp. 258-264.

46. La negativa de Ferrer Salat, en MARTíNEZ SOLER, José A., Los empresarios ante la crisis económica, p. 151; GONZÁLEZ FERNÁNDEZ, A., "De la neutralidad a la beligerancia. Empresarios y elecciones en la transición a la democracia», en RAMOS SANTANA, Alberto (coord.), La Transición: politica y sociedad en Andalucía, Cádiz, Ayuntamiento de Cádiz, 2005, pp. 197-210. 
a una crisis económica de ámbito internacional que intensificó los problemas estructurales de la economía española.

En ambos períodos la instrumentalización mutua que caracteriza las relaciones entre política y negocios experimentó una profunda quiebra. La desconfianza y la inseguridad ante el futuro provocó que determinados círculos empresariales apoyaran el cambio de régimen, actitud en la que, lógicamente, también influyeron motivaciones de orden ideológico. Como es natural, esa posición no fue compartida por los sectores identificados ideológicamente con el régimen anterior ni por aquellos otros -a veces los mismos, en ocasiones diversos-, que tampoco se sentían perjudicados, en materia económica, por las posibles disfunciones en sus relaciones con las esferas de poder político.

Así pues, no puede deducirse que el empresariado se oponga, por sistema y como un todo compacto, al cambio ni a los programas de reforma. Éstos pueden, evidentemente, suscitar temores y resistencias, aunque éstas serán menos si el programa reformista se lleva a cabo con una anunciada vocación de prudencia y moderación. En otras palabras, las suyas: desde el respeto a la economía de libre mercado y a la propiedad privada, consideradas como principios superiores y ajenos a las luchas partidarias. De otro lado, los empresarios, como colectivo, no pretenden cuestionar los nuevos poderes sino preservar su proximidad a los ámbitos de decisión política para intentar influir en la configuración del nuevo régimen. Con esa finalidad, reclamarán una participación directa en ese proceso tanto por su conocimiento inmediato de la realidad económica, de sus problemas y soluciones, como por su papel de ejecutores de la política elaborada en este ámbito. Al mismo tiempo, y éste suele ser un rasgo persistente en la cultura empresarial -en gran medida, en tanto que cultura española que es-, mantienen una profunda desconfianza hacia los políticos. En su caso específico, por la prioridad que los gestores gubernamentales conceden en demasiadas ocasiones, a cuestiones no relacionadas con la situación económica -que ellos entienden requiere medidas perentorias- $y$ por la ausencia de una identificación clara con sus intereses, que los empresarios suelen equiparar a los de la Nación.

Inicialmente, esa desconfianza genera actitudes defensivas y un discurso crispado y plagado de dramatismo que puede desencadenar, lo que no deja de resultar una paradoja para un grupo de interés que habría mostrado, ya en tiempos de la República, su prevención frente al corporativismo como un todo alternativo: la creciente desafección hacia un Estado que es percibido como parcial por su falta de representatividad, y la convicción de la necesidad de intervenir en la escena política sin intermediación de los partidos para erradicar ese déficit. $\mathrm{Y}$, en este punto, la existencia de un sistema asociativo único y jerarquizado proporcionó a los empresarios de los años setenta una capacidad de presión e influencia política superiores a los existentes en los años treinta. Un modelo asociativo posible, en gran medida, por la atribución de un estatus público a la organización cúpula empresarial, como a los sindicatos mayoritarios, por los nuevos poderes con la intención de ampliar el consenso a los actores sociales. La actitud de los actores políticos deviene, pues esencial. Lógicamente, no en lo que se refiere a la asunción de los intereses empresariales desde el poder o 
desde la oposición, sino al desarrollo de una política de pactos que permita la gestación de un nuevo marco institucional estable y sólido, asentado en la economía de libre mercado, y que garantice al mundo empresarial unas adecuadas expectativas de negocio. 